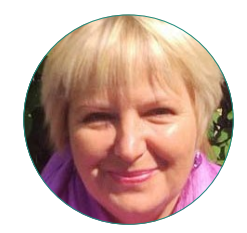

Е. Ю. Рождественская

\title{
ИНТЕРВЬЮИРУЯ ЭЛИТУ И СЕЛЕБРИТИ: СРАВНИТЕЛЬНЫЙ АНАЛИЗ ВОЗМОЖНОСТЕЙ И ОГРАНИЧЕНИЙ
}

\section{Правильная ссылка на статью:}

Рождественская Е. Ю. Интервьюируя элиту и селебрити: сравнительный анализ возможностей и ограничений // Мониторинг общественного мнения: экономические и социальные перемены. 2021. № 5. С. 64-91. https://doi.org/10.14515/monitoring.2021.5.1988.

\section{For citation:}

Rozhdestvenskaya E. Y. (2021) Interviewing the Elite and Celebrities: A Comparative Analysis of Methodological Opportunities and Limitations. Monitoring of Public Opinion: Economic and Social Changes. No. 5. P. 64-91. https://doi.org/10.14515/monitoring.2021.5.1988. (In Russ.) 
ИНТЕРВЬЮИРУЯ ЭЛИТУ И СЕЛЕБРИТИ: СРАВНИТЕЛЬНЫЙ АНАЛИЗ ВОЗМОЖНОСТЕЙ И ОГРАНИЧЕНИЙ

\section{РОЖДЕСТВЕНСКАЯ Елена Юрьевна-} доктор социологических наук, профессор факультета социальных наук, ведущий научный сотрудник МЛ ИСИ, Национальный исследовательский университет "Высшая школа экономики", Москва, Россия

E-MAIL: erozhdestvenskaya@hse.ru https://orcid.org/0000-0001-6874-2404

Аннотация. Статья посвящена методологическим и методическим вопросам интервьюирования представителей политической и бизнес-элиты с одной стороны и селебрити - с другой. Сравнительный анализ подходов к этим группам предполагает поиск сходств и различий в их характеристиках. Объединяющим моментом становится постепенная селебритизация элит, проявляющаяся в большей персонализации, включенности в дискурсы и перформансы публичной сферы и выборе надидеологической позиции в случае политических коммуникаций. В то же время наблюдается и встречный тренд по перетеканию селебрити в другие элиты, бизнес и политику - в терминах Редмонда, текучая селебритизация.

Селебрити концептуализируются как новая элита с ресурсом влияния в информационном обществе, но парадоксально отмечается ее безвластный характер. В статье предложен систематический анализ процессов интервьюирования при изучении политической и бизнес-элиты и элиты селебрити. Актуальность возможностей и ограничений метода интервью обнаруживается
INTERVIEWING THE ELITE AND CELEBRITIES: A COMPARATIVE ANALYSIS OF METHODOLOGICAL OPPORTUNITIES AND LIMITATIONS

Elena Yu. ROZHDESTVENSKAYA 1 -Dr. Sci. (Soc.), Professor at the Faculty of Social Sciences, Leading Researcher at the International Laboratory for Social Integration Research

E-MAIL: erozhdestvenskaya@hse.ru https://orcid.org/0000-0001-6874-2404

\section{${ }^{1}$ HSE University, Moscow, Russia}

Abstract. The paper considers the methodological and methodical issues of interviewing representatives of the political and business elite, on the one hand, and celebrities, on the other. Comparative analysis of approaches to these groups involves the search for similarities and differences in their characteristics. The unifying moment is the gradual celebritization of the elites, which manifests itself in greater personalization, involvement in the discourses and performances of the public sphere, and the choice of a supra-ideological position in the case of political communications. At the same time, there is a counter trend of celebrities flowing into other elites, business and politics - in Redmond's terms, liquid celebrity.

Celebrities are conceptualized as a new elite of a paradoxically powerless nature with a resource of influence in the information society. The author of this paper provides a systematic analysis of the interviewing processes used in the studies of the political and business elite and the celebrity elite. The relevance of the possibilities and limitations of the interview method is revealed against the back- 
на фоне преимущественного дискурсивного/текстуального анализа селебрити, равно как и обращения к нереактивным данным в случае изучения элит. Анализ исследовательского дискурса элит и селебрити структурирован по проблеме определения той или иной социальной группы, обоснованию методологического выбора в пользу интервьюирования, стратегиям получения доступа, контролю над ситуацией интервью, обеспечению баланса власти в ситуации интервью, а также баланса репрезентации и идентичности. В качестве результата анализа предложены рекомендации по упомянутым ключевым моментам интервьюирования селебрити и представителей других элит. Приведенные в статье эмпирические иллюстрации из исследований призваны обозначить описанные проблемные моменты в интервью.

Интервьюирование знаменитостей имеет особенность: у них слишком часто берут интервью, что снижает мотивацию к участию в академических исследованиях. Проблема доступа к селебрити для социологического интервьюирования может быть решена через гейткиперов, социальные сети или методом снежного кома при наличии первичного ключевого знакомства. Важен и эпистемологический момент, проявляющийся через дискурс persona studies - различение у интервьюируемого селебрити трех перформативных уровней: публичной личности, конструируемой частной личности и "реальной" частной личности.

Ключевые слова: элиты, знаменитости, интервью, стратегии интервью, методология ground of the predominantly discursive/ textual analysis of celebrities, as well as the appeal to non-reactive data in the case of studying the elites. The analysis of the research discourse of elites and celebrities embraces the problems of determining a particular social group, substantiating the methodological choice in favor of interviewing, choosing strategies for gaining access, controlling the interview progress, ensuring a balance of power in the course of the interview and securing the balance of representation and identity. Basing on the study results, the author proposes recommendations on the above-mentioned key points of interviewing celebrities and representatives of other elites. The empirical ilIustrations from research presented in the paper are intended to highlight the problematic points of the interviews.

Generally, celebrities are interviewed too often, which reduces the motivation to participate in academic research. The problem of access to celebrities for sociological interviewing can be solved through gatekeepers, social networks or using the snowball method if there is a primary key acquaintance. An epistemological moment is also important, which manifests itself through the discourse of persona studies highlighting the distinction in the interviewed celebrity of three performative levels: the public personality, the constructed private personality and the "real" private personality.

Keywords: elites, celebrities, interview, interview strategies, methodology 
В статье обсуждаются вопросы методологии и методики интервьюирования двух групп: представителей политической и бизнес-элиты с одной стороны и селебрити $^{1}$ - с другой. Автор проводит сравнительный анализ подходов, что предполагает поиск сходств и различий в характеристиках этих групп. Объединяющим моментом становится постепенная селебритизация элит, проявляющаяся в большей персонализации, включенности в дискурсы и перформансы публичной сферы и выборе надидеологической позиции в случае политических коммуникаций. Политические и бизнес-элиты приоткрываются для общества, а селебрити конвертируют свой социальный капитал узнаваемости в широкое социально-политическое влияние. Подобная конвергенция актуализирует внимание к методолого-методической стороне изучения как элит, так и селебрити.

Анализ литературы показывает, что в исследованиях селебрити к настоящему моменту сложился преимущественно дискурсивно-текстуальный аналитический подход [Turner, 2010], в то время как при изучении элит принято обращение к нереактивным данным. Тем не менее структура публичного интервьюирования селебрити балансирует между целью повлиять на поведение потребителей и перформансом, претендующим на подлинность репрезентации героя. Как же тематизируется в социологии проблематика непосредственного face-to-face интервьюирования с представителями элит, обладающих властью, и селебрити, обладающих влиянием? Для ответа на этот вопрос автор статьи последовательно обращается к двум основным сюжетам: интервьюированию элиты (раздел 1) и интервьюированию селебрити (раздел 2),--структурируя их по таким сравнимым аспектам, как определения, специфика процесса интервью и его организации, проблемы связи и доступа к представителям группы, а также контроля и доминирования во время беседы.

\section{1. Определения элиты}

В основном методологическая литература обсуждает историю понятия элиты, границы этого понятия с учетом реконфигурации элитных групп, каналы рекрутинга и актуальные проблемы капсулирования и фрагментации элит ${ }^{2}$. Термин "элита" в социальных исследованиях можно проследить до начала 1900-х годов, когда индивиды с выдающимися талантами в любой области считались меритократической элитой, что обуславливало право управлять другими [Woods, 1998]. К 1950-м годам теоретизирование приняло функциональное направление, определяя "властные элиты" как законодателей, судей, военных и руководителей бизнеса. Далее линия обсуждения переключилась на содержание власти и привилегии элит [Odendahl, Shaw, 2002], их позиции в бизнес-сетях [Undheim, 2003]. Исследователи также классифицируют элиты по различным категориям. Согласно Келлеру (цит. по [Odendahl, Shaw, 2002]), "стратегические элиты” могут быть определены как элиты с устойчивым социальным влиянием. В силу своих позиций или ресурсов

\footnotetext{
1 В статье понятие "селебрити" используется синонимично понятию "знаменитости". Предпочтения автора в пользу этого термина обусловлены предметом исследования-дискурсом селебрити, который сложился в основном в англоязычной научной литературе.

2 В отечественном контексте это широкое междисциплинарное поле представлено целым рядом исследователей, среди которых В.Гимпельсон, И. Бунин, И. Куколев, В. Радаев, О. Шкаратан, Т. Заславская, Е. Орех, А. Дука, О. Крыштановская, С. Перегудов, С. Барсукова, А. Чепуренко, В. Ледяев, А. Чирикова, Д. Тев и другие.
} 
они способны влиять на развитие общества или принимать относительно него принципиальные решения. К этому общему определению возможны существенные дополнения, как у Пьера Бурдьё, который к аргументам о "доминирующем принципе господства" в поле власти присоединяет и "преобладающий принцип легитимности" власти. Поэтому вклад Бурдьё заключается в увязывании легитимности господства и социального неравенства. Кроме того, он сосредоточил свое внимание на "структурах власти" и на специфической логике позиций на арене борьбы, преобладающих способах восприятия, мысли и действия, легитимных механизмах воспроизводства элит, а не на профиле представителей этих групп [Bourdieu et al., 1991]. Ведущий немецкий элитист Михаэль Хартманн вводит контрастное по подходу с Бурдьё дополнение к упомянутому определению. Его занимал именно профиль представителей элиты и пути их рекрутинга. Он даже вводит уточнение: господствующий класс, позиционная элита, которую составляют члены советов директоров в крупных корпорациях - те, кто по социальному происхождению, образовательным капиталам и хабитусным характеристикам принадлежит к гораздо более широкому социальному слою [Hartmann, 2002], чем топ-менеджеры, которых относил к концентрированной властной элите его предтеча Райт Миллс. Ведь элита состоит не только из небольшой группы носителей властных позиций, но также из той социальной среды, которую составляют около $4 \%$ населения и из которой преимущественно рекрутируются обладатели высших позиций. В целом использование термина "элита", как правило, соотносится с конкретной национальной социальной структурой. Поэтому история теорий элиты всегда рассматривает эту группу в контексте ее возникновения, различая, например, исторически сложившиеся национальные способы рекрутинга в элитные группы.

Однако сегодня, например, положение человека в компании - не показатель стабильного элитного статуса; определенные акторы считаются членами элиты, поскольку занимают стратегические позиции в социальной сети и действуют как важные посредники между социальными структурами [Burt, 2000]. Более того, элитный статус может быть привязан к месту и времени, как утверждает Уильям Харви [Harvey, 2010]. Например, индивид может быть причислен к элите в одном конкретном регионе, но не в другом. То есть статус представителя элиты не статичен, поскольку со временем можно обрести или потерять его. Меняются и границы определения элит: как справедливо отмечают Сэвидж и Уильямс [Savage, Williams, 2008: 13], 70\% компаний из списка FTSE $100^{3}$ в начале 1980-х годов были представлены в индексе и в первой декаде этого века, однако остальные, выйдя из него, уже не представляют корпоративную власть.

Наиболее распространенными элитными группами являются бизнес- или корпоративные, политические, профессиональные и социальные элиты, которые позиционируются как не исключающие друг друга [Hertz, Imber, 1995; Morris, 2009; Odendahl, Shaw, 2002]. Делани определяет как «ультра-элиты» тех, кто находится на топ-позициях крупных организаций [Delaney, 2007]. Наконец, Андхайм [Undheim, 2003] отделяет экспертов от представителей элит, описывая первых как узких специалистов, а вторых как универсалов. Таким образом, есть несколько

\footnotetext{
${ }^{3}$ The Financial Times Stock Exchange 100 Index - ведущий индекс Британской фондовой биржи.
} 
способов определить, кто может квалифицироваться как элита на основании атрибутирования, поведения и отношений, и существует множество способов их дальнейшего обозначения.

Исторически сложилось так, что многие дисциплины социальных наук были выстроены на опыте применения количественных исследований, а потому игнорировали опыт элит, которые были недостаточно многочисленными для включения в выборочные обследования [Savage, Williams, 2008]. Однако признание важности качественных методов наряду с количественными в последние десятилетия привело к возрождению этнографических исследований, включая наблюдение и интервью, и росту популярности лонгитюдных исследований элит [Harvey, 2010].

\section{Выбор метода интервью при изучении элит}

Интервьюирование элитных групп ограниченно представлено в социологической методической литературе по вполне понятным причинам: к этой категории информантов сложно получить доступ, и даже в случае успеха в интервью складывается асимметрия власти, проявляющаяся как доминирование. Для доступа к элитам необходимо понимание контекста этой социальной группы, а также применение особых стратегий вовлечения собеседников в интеракцию, планирования интервью и подготовки к нему; стратегий, способствующих взаимопониманию в процессе интервью. Эффективное интервьюирование позволяет, как утверждает Харви, генерировать новые содержательные данные [Harvey, 2010].

Корпус методической литературы, посвященной интервьюированию элит, невелик [Odendahl, Shaw, 2002; Thomas, 1995; Welch et al., 2002]. Еще в 1995 г. Герц и Имбер объясняли подобное положение дел следующим образом:

Исторически сложилось так, что бизнес-элиты были наиболее трудной группой с точки зрения доступа для социологов. Иерархия бизнес-организаций предназначена для защиты тех, кто там работает, и для удержания посторонних от того, чтобы больше узнать о том, как они работают [Hertz, Imber, 1995: 35].

В основном научная литература по проведению интервью с представителями элит сфокусирована на определении и категоризации этих групп, решении проблем доступа и неравенства позиций интервьюера и интервьюируемого [Delaney, 2007; Dexter, 2006; Harvey, 2010; Hertz, Imber, 1995; Richards, 1996; Odendahl, Shaw, 2002]. Кроме этого обсуждаются вопросы понимания контекста различных элитных групп и их специфических норм как детерминант формата интервью и того, кто может получить мандат на интервьюирование, а также роль прагматизма и профессионализма в получении доступа к элите и ее изучению [Cochrane, 1998; Dexter, 2006; Hirsch, 1995; Odendahl, Shaw, 2002; Ostrander, 1993; CunninghamSabot, 1999; Yeung, 1995].

Приведем пример изучения американской медицинской элиты. Элен Голдман и Сюзан Суэйз описывают в своем исследовании специфику сферы здравоохранения в США - больниц и системы медицинского обслуживания [Goldman, Swayze, 2012]. В указанной области практически не существует методических рекомендаций по дизайну исследования, предполагающего проведение интервью с пред- 
ставителями элиты. Нормы, которые важно понимать в этом контексте, включают исторически сложившуюся традицию по использованию коротких телефонных интервью. Кроме того, запросы на вовлечение в исследования обычно проверяются профессиональными организациями, рекомендующими своим членам принимать или не принимать участие. Наконец, немногие руководители больниц и системы здравоохранения включаются в качественные исследования, что может ограничивать их значимость для представителей элит и дополнительно снижать желание полноценно принимать в них участие. Свою работу исследовательницы начали с просмотра веб-сайта организации и поиска информации о ее руководстве и об обслуживаемом ей регионе. Это позволило получить представление об истории организации и ее услугах, познакомиться с биографиями генерального директора и членов правления, систематизировать сведения о географии региона, его предприятиях, ресурсах, важных исторических и общественных событиях. При подтверждении времени собеседования помощников спрашивали, происходило ли в этот день что-нибудь особенное, что могло бы повлиять на график генерального директора или доступ исследователя к нему.

Затем в своей работе авторы используют метод глубинного интервью по версии Зайдмана [Seidman, 1998], суть которого состоит в трехэтапном процессе выявления потенциальных участников, установлении контакта с ними и обеспечении обязательства участвовать. К интервью удалось привлечь квалифицированных консультантов по стратегии здравоохранения и руководителей национальной ассоциации здравоохранения, в состав которой входят больницы и системы предоставления медицинских услуг. Эти группы были выбраны из базы потенциальных участников из-за их обширных знаний в области здравоохранения, регулярного контакта с остальными представителями группы и признания их ведущей экспертной роли. Отобранные для интервью консультанты были определены в результате анализа отраслевых публикаций и программ конференций. В итоге число ключевых персон для интервьюирования вошли руководитель, специалист, ответственный за стратегию и политику учреждения, и глава совета директоров по стратегическому планированию. С ними связались в письменной форме и попросили указать двух или трех человек, с которыми они работали и которые соответствовали определению опытного стратега в медицинской сфере. Такой качественный критерий отбора обеспечил фокус на профессиональных качествах интервьюируемых. Этот прием известен как "социальная маркировка" и широко используется для выявления участников исследования в изучении формирования экспертных знаний [Richards, 1996; Yeung, 1995; Sternberg, 1999]. Описанная стратегия выявила 36 возможных участников, статус которых соответствовал позиции генерального директора (CEO), хотя должность не была указана в качестве критерия отбора. Другие исследователи сходным образом описывают процесс выявления потенциальных участников как специфический для конкретной профессиональной ситуации и отрасли [Dexter, 2006; Odendahl, Shaw, 2002; Richards, 1996; Useem, 1995; Yeung, 1995].

Поскольку корпоративная элита - это влиятельные, известные и/или хорошо информированные люди в организации, интервью с ними дает множество преимуществ. Из-за своего положения представители управленческой элиты 
могут располагать информацией, которой нет у других сотрудников: они могут предоставить подробное описание организации и обсудить внешние отношения с контрагентами; они, вероятно, будут лучше ориентироваться в юридических и финансовых структурах, а также смогут обсудить организационную политику и планы на будущее [Marshall, Rossman, 1999].

В то же время есть множество проблем при проведении интервью с представителями элиты. Как было упомянуто ранее, в научной литературе рассматриваются две общие проблемы: получение доступа и конфронтация с доминированием во время интервью [Harvey, 2010]. Проблемы с доступом связаны с трудностями в контакте с элитой, вероятным отсутствием обратной связи и плотностью их графика [Marshall, Rossman, 1999]. На следующих этапах могут возникнуть многочисленные препятствия во время интервью, в том числе - попытки представителей элиты контролировать процесс и расспрашивать интервьюера о различных элементах исследования. Как отмечает Каннингам-Сабо [Cunningham-Sabot, 1999], интервьюируемые из элитной группы могут занять "оборону", проявляя препятствующие сотрудничеству модели поведения, поскольку они чувствуют угрозы или риски; однако они могут быть открыты, считая академические исследования ценными для общества и стремясь внести свой вклад. Некоторые авторы предлагают идеи по преодолению описанных проблем - впрочем, эти предложения носят общий характер и должны быть адаптированы к конкретной исследовательской ситуации и культуре элитной группы [Cochrane, 1998; Dexter, 2006; Hirsch, 1995; Odendahl, Shaw, 2002; Ostrander, 1993; Cunningham-Sabot, 1999; Yeung, 1995].

Получение доступа. Как отмечалось выше, бо́льшая часть литературы по интервьюированию элит посвящена проблемам получения доступа к информантам [Delaney, 2007; Dexter, 2006; Harvey, 2010; Richards, 1996; Odendahl, Shaw, 2002]. Решение этой задачи начинается с выявления потенциальных участников. В методической литературе предлагается изучать списки предприятий, базы данных, каталоги и публикации, а также использовать личные контакты (при их наличии) и методы выборки снежного кома (поле не открывается сразу, оно «приоткрывается"), чтобы определить, у кого брать интервью [Dexter, 2006; Odendahl, Shaw, 2002; Thomas, 1995; Yeung, 1995]. Несмотря на свою эффективность, эти стратегии могут привести к выявлению участников, которые могут не иметь глубоких знаний об изучаемом феномене [Odendahl, Shaw, 2002].

Для связи с потенциальными участниками в научно-методической литературе рекомендуется обращение к влиятельному человеку или своим знакомым для посреднического представления, отправка убедительного вступительного письма с указанием цели исследования и его преимуществ для участников, а также упоминание любой институциональной поддержки, что может придать легитимность исследованию [Delaney, 2007; Richards, 1996; Thomas, 1995; Yeung, 1995]. Впечатления от первого контакта будут положительными, если на первичном этапе удастся продемонстрировать хорошую академическую подготовку и продуманность исследования [Lilleker, 2003]. Другие советы предостерегают от использования сугубо академического языка и слишком пространного описания самого 
проекта - это может привести к тому, что исследователь будет перенаправлен к штатному специалисту, но не получит доступ к элите [Dexter, 2006].

В методологической литературе признается значимость контроля гейткиперов элиты. Секретарь-референт изображается либо как препятствие, которое нужно обойти, либо как защитник-помощник, который будет транслировать исследователям то, что они хотят: например, информацию о встрече с представителями элиты, если исследователи достаточно вежливы и настойчивы в своих просьбах [Cochrane, 1998; Dexter, 2006; Richards, 1996; Undheim, 2003]. Харви [Harvey, 2010] предлагает иной взгляд на гейткиперов, рассматривая их как потенциальные возможности, и описывает встречу с референтом для описания своего исследования, в результате которой его направили к 60 потенциальным участникам. Одендаль и Шоу характеризуют процесс установления контактов с представителями элиты как «требующий стратегий, сочетающих изобретательность, социальные навыки, контакты, осторожные переговоры и удачные обстоятельства" [Odendahl, Shaw, 2002: 307].

В то же время в литературе содержится мало сведений о том, как исследователям следует поступать в ситуации, когда элита отказывает в участии. Андхайм [Undheim, 2003] отмечает: знание того, почему представители элиты согласятся или откажутся участвовать, должно быть частью программы исследования; Каннингам-Сабо [Cunningham-Sabot, 1999] и Томас [Thomas, 1995] советуют подчеркивать желание исследователя понять социальный мир с точки зрения элиты. Делани дает исследователям схожие рекомендации: “Обозначьте в переговорах, что человек, у которого вы хотите взять интервью, внесет важный и даже уникальный опыт в эту тему, а их конкретный опыт и знания имеют решающее значение для полного понимания рассматриваемой проблемы" [Delaney, 2007: 212]. Однако эти предложения сформулированы с точки зрения исследователя, но не самих участников, и предполагают, что элита являет собой открытую группу, заинтересованную в проведении исследований [Cunningham-Sabot, 1999]. Декстер [Dexter, 2006] считает привлекательной для элиты возможность рассказать или представить свою версию институциональной истории, что равнозначно удержанию интерпретативной власти в своих руках.

Возвращаясь к исследованию Голдман и Суэйз, отметим, что для доступа к руководителям учреждений системы здравоохранения (как представителей медицинской элиты) и их вовлечения в интервью успешной оказалась комбинация следующих стратегий: повторное переопределение элиты как экспертной группы известными стратегами в области здравоохранения; указание на то, что это исследование спонсировалось университетом, чтобы выгодно сопоставить его с консалтинговыми исследованиями, которые часто считаются предвестниками продаж; и указание на то, что участие элиты в исследовании поможет развитию лидерских качеств будущих руководителей здравоохранения [Goldman, Swayze, 2012]. Примечательно, что последняя стратегия возникла в результате разговора с представительницей медицинской элиты, которая во время первоначальной телефонной беседы проинструктировала исследователя относительно лучших подходов к своим коллегам - отметив, что ее коллеги чрезвычайно заняты, но также обеспокоены судьбой своего наследия, и было бы перспективно оформить запрос как способ систематизировать их опыт, чтобы другие могли на нем учиться. 
Любопытна и кода проведенного исследования с методической точки зрения: по его завершении всех участников спросили, почему они решили участвовать. Большинство отметили, что им очень помог самоанализ и их никогда раньше не опрашивали на эту тему, интервью даже сравнивали с психотерапией. Причины их первоначального согласия варьировались от чистого любопытства и желания помочь другим до их давнего интереса к стратегии развития здравоохранения и способам ее улучшения [Goldman, Swayze, 2012]. Таким образом, представители элиты участвовали не оценивая, "что это дает мне" или "оправдались ли для меня время и затраты", а ориентируясь на предполагаемый экспертный вклад.

Контроль над ситуацией в интервью. Исследователям рекомендуется проявлять гибкость при планировании интервью с элитой, учитывать предпочтения интервьюируемых относительно времени и места его проведения, чтобы обеспечить их удобство и комфорт [Harvey, 2010; Odendahl, Shaw, 2002; Thomas, 1995]. Обед, который является обычным поводом для деловых обсуждений, не считается хорошим временем для интервью, поскольку общественное место, скорее всего, ограничит беседу общим разговором [Dexter, 2006]. Делани признает, что элиты вправе диктовать время и место проведения интервью с глубиной планирования до нескольких недель или месяцев [Delaney, 2007]. В то же время он советует использовать "давление календарного плана" - например, подстраивать предложения под их приезд в город на конференцию, чтобы облегчить планирование и иметь временные границы. Одендаль и Шоу [Odendahl, Shaw, 2002] по следам своего опыта высказывают опасения, что элиты могут заставлять исследователей ждать в течение длительного времени, сообщать по прибытии, что время встречи значительно сокращается, или прерывать интервью из-за занятости, не заменяя упущенного времени. Подготавливаясь к интервью, исследователям рекомендуется выполнить своего рода домашнее задание, чтобы понять культуру, контекст и социальные нормы той элитной группы, в которую они входят, включая стиль одежды и ритуалы взаимодействия между элитами [Odendahl, Shaw, 2002; Ostrander, 1993; Richards, 1996; Thomas, 1995], хотя никаких конкретных указаний относительно того, как раскрыть эту информацию, не дается. Другой совет по подготовительной фазе интервью предлагает заранее отправить гайд с вопросами по интервью, чтобы продемонстрировать профессионализм, помочь с проблемами контроля и максимально эффективно использовать время интервьюируемого. Однако подобное предварительное уведомление не было поддержано, напри мер, Зайдманом [Seidman, 1998], предпочитающим, чтобы вопросы возникали в результате эмпатийного слушания и активного вопрошания со стороны исследователя; с его точки зрения, это стимулирует готовность интервьюируемого делиться своим опытом.

Установление властного баланса и взаимопонимания. Предполагается, что элиты, привыкшие к высокому статусу и руководящей роли, будут пытаться контролировать и процесс интервью, постоянно подвергая сомнению методы исследования, формулировки вопросов, направление беседы и полномочия исследователя. Эти формы контроля могут вылиться в попытки изменять и переформулировать вопросы, давать встречные уточняющие реплики, доминировать с помощью сложных ответов и оценочных суждений, а также в целом использо- 
вать интервью, чтобы представить себя только в положительном свете [Delaney, 2007; Morris, 2009; Odendahl, Shaw, 2002; Ostrander, 1993; Welch et al., 2002]. Большие возрастные и гендерные различия также полагаются потенциальными препятствиями для серьезного отношения к интервьюеру [Cochrane, 1998; Odendahl, Shaw, 2002].

Ниже в целях эмпирической иллюстрации приведен транскрипт из интервью ${ }^{4}$ с представителем российской деловой элиты (глава госкорпорации). Он содержит поочередные вопросы и реплики интервьюера и интервьюируемого, некоторые из которых выделены автором статьи. Это смысловое выделение призвано проиллюстрировать дискурсивные формы сопротивления статусного респондента: оценка вопросов, перехват инициативы и внесение собственного ритма в разговор, встречные вопросы, квалификация вопросов как некорректных, саботаж, сомнение в квалификации интервьюера, переадресация собственных затруднений разработчикам исследования через голову интервьюера.

И.: Какие факты в вашей профессиональной деятельности вы считаете ключевыми?

P.: Вопрос неожиданный, точно не имеет отношения к примерному перечню вопросов, который мне раньше давали. Он простой, с одной стороны, с другой, достаточно сложный...

И.: Что вы думаете о будущем вашей профессиональной деятельности?

P.: У меня в этом смысле ответ достаточно стандартный. Есть, или бывают, поручения или предложения, от которых нельзя отказаться, и в этом смысле - куда Родина направит, что называется, там и будет реализовываться моя профессиональная деятельность. Что касается текущей ситуации, то никаких внутренних мотивов, связанных с изменением места работы, у меня нет.

И.: Мотивов нет-но, очевидно, вы строите какие-то планы, имеете в виду какую-то перспективу... Не спрашивая о том, какие это планы и перспективы,- на каком временно́м горизонте вы строите ваши профессиональные планы?

P.: Еще раз повторюсь - если будут какие-то предложения или поручения, от которых нельзя будет отказаться, то временной горизонт будет определен такого рода поручениями и предложениями. Если говорить о работе в режиме "по собственному желанию", то это, наверное, история не менее чем 5-10 лет.

И.: Вы видите свое будущее как профессионала в России или за рубежом?

P.: Не, в России. Странный вопрос, если честно. Я не знаю, был ли хоть один из интервьюируемых, который ответил на этот вопрос: "за рубежом"...

И.: От чего зависит реализация ваших профессиональных планов?

P.: Подождите. Я же на самом деле ответил целиком, какие факторы. У нас факторов достаточно много. [Долго перечисляет]

И.: Извините, прерву. Вы сейчас говорите о том, что военные называют "вводные" для тех проектов, которые вы осуществляете, сидя за вашим рабочим столом...

P.: О работе в целом, конечно. Это не всегда проекты, функция...

\footnotetext{
${ }^{4}$ Отрывок из интервью заимствован из материалов проекта по изучению мнений политической и бизнес-элиты, в котором принимала участие автор статьи. Проект обладает закрытым статусом, поэтому имена, даты и специфика занятости анонимизированы.
} 
И.: А если говорить именно о вашей профессиональной деятельности - вопрос о вас, не о том, что вы делаете, а о том, что делаете вы.

\section{Р.: Разница есть?}

И.: Есть - я акцент перенес со "что" на "кто". Вот на вас какие-то факторы влияют? Что для вас существенно?

Р.: Ну, на самом деле, все из перечисленного в той или иной степени. Другое дело, что "на вас влияет" - это всегда через "что", влияние оказывается всегда через реализацию какого-то проекта или выполнение какой-то функции.

И.: О чем вы думаете в первую очередь, когда речь заходит о вашем будущем, о будущем вашей семьи?

Р.: Хороший вопрос. Ну, он несколько странный, если честно, без контекста. На него почти невозможно ответить в таком залоге, как вы его сейчас задаете. Какой вызов есть, такой и... Реакция адекватна вызову, что называется.

И.: А если вопрос вот такой максимально нейтральный и общий, то...

Р.: Я ответил, на самом деле. Вопрос, с моей точки зрения, сформулирован несколько странно и некорректно, и ответ на него я, собственно, тоже дал. Подругому я даже затрудняюсь ответить. Если вы хотите услышать ответ, который в каком-то смысле более корректен, то и вопрос должен быть более акцентирован, что ли. А это вопрос из серии: “А о чем вы всегда думаете в первую очередь?" Вот что на него можно ответить? Или "...когда встаете с утра?"

И.: Это от чего-то зависит? От вас или...?

P.: Все ответы можете написать сами. Как в одном из фильмов было сказано, что бы человек ни делал...

И.: А что вас больше всего тревожит, когда вы думаете о будущем?

P.: Ну, пожалуй, у меня нет ответа на этот вопрос в таком залоге, потому что он такой странный вопрос с точки зрения того, что ответов может быть два. "Ничего" и "все". И.: выберите любой ответ между этими двумя.

И.: То есть ничего конкретного вам не приходит в голову из потенциального перечня "BCe"?

Р.: Вы же задаете общий вопрос, я и отвечаю в общем формате. Конкретика разная...

И.: Хорошо. Кстати. Когда мы говорили об этих вещах - о будущем вашем, вашей семьи, - когда вы говорите об этом, вы какой временно́й горизонт имеете в виду? Будущее на сколько вперед?

Р.: Хороший вопрос. А вы от меня какого ответа ждете?

И: Примерного.

P: Вы тогда неправильно формулируете вопрос. Может, я их не понимаю, готов допустить. Еще раз: в том залоге, как этот вопрос был озвучен, нет границ по поводу думания о будущем детей или семьи...

И.: Вот. Я услышал.

P.: [вздыхает] Ну на самом деле - я не знаю, кто вам писал вопросы, они все-таки не очень хорошие, я бы по-другому их формулировал, чтобы на них можно было отвечать. 
Отметим, что в транскрипте задокументирована ситуация, потенциально указывающая на социально и психологически конфликтный момент. Интервьюер, с извинением прервавший собеседника, взял на себя смелость оценить ответ статусного респондента: “Вы сейчас говорите о том, что военные называют „вводные“ для тех проектов, которые вы осуществляете, сидя за вашим рабочим столом... А если говорить именно о вашей профессиональной деятельности - вопрос о вас, не о том, что вы делаете, а о том, что делаете вы". Оценка в сочетании с понадобившимся по контексту пояснением со стороны интервьюера поставила респондента в неловкое положение. Очевидно, это послужило укреплением последнего в мысли, что его экспертиза поставлена под сомнение и простимулировала оборонительный и даже агрессивный характер его реплик.

С методической точки зрения предлагаемые далее решения (в отношении баланса власти в процессе интервью) заключаются в том, что интервьюер должен прибыть первым, чтобы установить диктофон и определить рассадку, установить контроль, вначале вручив свою визитку; занимать коллегиальную (а не почтительную) позицию, сохраняя вежливость и профессионализм; предложить краткое введение с разъяснением основных правил; поощрять открытую позицию; переходить от вопросов, не вызывающих затруднение, к более сложным [Delaney, 2007; Morris, 2009; Odendahl, Shaw, 2002; Ostrander, 1993; Richards, 1996; Thomas, 1995].

В упоминавшейся работе Голдман и Суэйз исследовательницы выстраивали доверие в самом интервью, опираясь на предложенные в других работах приемы: комментарий об учреждении, изображенном на настенной фотографии, дипломах или наградах [Odendahl, Shaw, 2002]; использование сведений из реферативных источников для создания доверительных отношений [Kezar, 2003]; объяснение того, что запись необходима, чтобы исследователь мог слушать, а не делать заметки; повторное использование формулировок информированного согласия о защите конфиденциальности элит для снятия этой напряженности; описание интервью как процесса совместного обучения [Morris, 2009]; указания на то, что не существует "правильных" или "неправильных" ответов, но есть ценный для исследования опыт представителей элиты.

\section{2. Селебрити как новая элита}

Переключение на специфическую элиту - селебрити - и ее анализ методом интервьюирования требует интервенции в специфическую дисциплинарную область, сложившуюся и динамично развивающуюся в последние десятилетия. Элиты и селебрити объединяет происходящая селебритизация элит, проявляющаяся в большей персонализации, медийной узнаваемости и включенности в дискурсы и перформансы публичной сферы, а также в надидеологической позиции представителей элиты в политических коммуникациях. Но заметен и встречный тренд перетекания селебрити в другие группы элит, бизнес и политику. Это сращивание Редмонд называет текучей селебритизацией (liquid celebrity) [Redmond, 2010]. Новый тренд заключается также в концептуализации знаменитостей как новой элиты в информационном обществе [Grinin, 2012], сопровождаемой, однако, парадоксально безвластным характером этой элиты селебрити: власть заменяется феноменом влияния [Alberoni, 1962/2006]. 
В представлении Адорно, селебрити - это люди, которые добились известности благодаря таланту или успеху в индустрии популярной культуры: кинозвезды, музыканты, телеведущие и т.д. [Adorno, 1991]. Распространение реалити-шоу и социальных сетей создало звезд, зажигающихся благодаря более демократичным и одновременно менее ориентированным на таланты медиа каналам [Turner, 2004; Currid-Halkett, 2010]. Определяющим и неизменным элементом знаменитости является не его одаренность, а связь с большой частотой сообщений о нем в СМИ: это “человек, известный тем, что он известен" [Boorstin, 1962/1992: 21]. Кроме того, признаком знаменитостей является высокая задокументированность их времяпрепровождения с другими очень заметными людьми, о чем пишет Маршалл [Marshall, 2010], называя частые появления персонажа в публичном медийном пространстве "перформансом" и "внетекстуальным измерением" [Marshall, 2006]. Отталкиваясь от данного Бурстином определения, можно сформулировать дефиницию селебрити как персонажей, которые переступающих некоторую частоту визуальной документации в СМИ и популярной прессе вместе с другими публичными деятелями на социально значимых мероприятиях. В этой дефиниции явно использован эффект перформативной сатурации: “Известные прежде всего своей известностью, знаменитости усиливают их образы знаменитостей благодаря широко известным отношениям друг с другом. Путем своего рода симбиоза знаменитости живут друг за счет друга» [Boorstin, 1962/1992: 65].

Социологически знаменитостей можно рассматривать как 1) личностей и как 2) специфические группы - если анализировать взаимосвязи в контексте их социальных сетей. Исследователи Рэвид и Каррид-Халкетт [Ravid, Currid-Halkett, 2013: 184] отмечают, что сформировались четыре фокуса изучения селебрити:

- «победитель получает все» на рынках суперзвезд [Rosen, 1981; Adler, 1985; MacDonald, 1988; Frank, Cook, 1995; Cowen, 2000],

- актеры и гейткиперы, участвовавшие в раскручивании и продвижении знаменитостей [Gamson, 1994; Turner, 2004, 2010],

- отношения между знаменитостями и их публикой или фанатами [Braudy, 1986; Marshall, 1997],

- а также процесс коммодификации образов знаменитостей в рекламе и потреблении [Argawal, Kamakura, 1995; Baym, 1993].

Таким образом, селебрити становятся все более и более значимой особой группй в современном обществе с его медиатизацией, появлением реалити-шоу, таблоидов знаменитостей, а также социальных сетей, посвященных исключительно протоколированию жизни знаменитостей [Braudy, 1986; Gamson, 1994; Turner, 2004; Marshall, 2010].

Наиболее значительный вклад в изучение селебрити внесли культурологи и исследователи медиа, позиционирующие этот феномен как функцию конструи рования СМИ и стимулирование реакций публики [Marshall, 2010]. В литературе одним из важнейших компонентов культуры знаменитостей является взаимодействие между фанатами или вовлеченной аудиторией и знаменитостью [Jenkins, 2006]. Масштабирование знаменитости символизирует ее связь с аудиторией, и, следовательно, внимание публики необходимо для того, чтобы вызвать культивирующую эффект узнаваемости реакцию. СМИ - важный посредник в этой 
динамике, сосредотачивающий интерес и внимание на индивидуальном уровне персоны-селебрити. Таким образом, СМИ создают "псевдособытия" [Boorstin, 1962/1992] или то, что Маршалл [Marshall, 2010] называет "внетекстуальными измерениями", посредством которых формируются знаменитости, участвующие в капиталистическом производстве массовых товаров и потребительской информации для публики.

Исключительность знаменитостей по отношению к другим социальным категориям и группам имеет парадоксальный характер, ведь многие из них являются выходцами из разных социальных слоев, в том числе и низкостатусных. Однако, достигнув позиции селебрити, они становятся членами социальной сети наравне с другими знаменитостями, что реципрокно укрепляет их статус [Boorstin, 1962/1992]. При этом объединяющее селебрити уникальное качество, по мнению Рэвид и Каррид-Халкетт [Ravid, Currid-Halkett, 2013] заключается в опоре на документализирующие их функционирование СМИ: они подтверждают, что такая категория существует, благодаря сообщениям об эксклюзивности заведений, мероприятий и социальных сетей, частью которых они являются,- - независимо от отрасли их деятельности или того, считаются они талантливыми или бездарными.

С начала 2000-х годов предпринимались попытки разработать приемлемую номенклатуру для исследования знаменитостей. Например, Роджек классифицировал общепринятые и адаптированные им категории статуса селебрити как достигнутые вследствие таланта и успеха в условиях конкуренции, предписанные по факту рождения в соответствующих известных кланах и приписанные ввиду участия в медиа форматах [Rojek, 2001]. Последнюю категорию селебрити с приписанным статусом звезды, порожденным вниманием публики и простимулированным СМИ, Роджек предложил обозначить как селетоид (celetoid) [ibid.: 185] - с очевидной аллюзией на быстротечность проходящей славы астероида, но не звезды. Другие, как упоминалось выше, пытались определить знаменитость как "внетекстуальную" категорию, чтобы отличить ее медийную известность [Marshall, 2014]. Чтобы зафиксировать момент, когда частный гражданин внезапно переходит в статус знаменитости, была выдвинута идея "случайной знаменитости" [Turner et al., 2000]. Другие авторы тематизировали границу между селебрификацией как процессом превращения в знаменитость и селебритизацией как мета-процессом медиатизации [Driessens, 2013d]. Дальнейшие усилия привели к продумыванию терминов для описания преобразования стоимости знаменитостей, их капитализации и идеи "остаточной ценности" [Currid-Halkett, 2010] и связанных “звездных капиталов" [Driessens, 2013b] - с целью описать влияние селебрити, переходящее в другие сферы общества.

Дискутируя с Маршаллом как сторонником внетекстуального происхождения селебрити, Грэм Тернер привлекает внимание к тому, что структурно эту группу можно рассматривать как репрезентацию, дискурс, индустрию и культурное образование [Turner, 2010]. Во-первых, знаменитость - это жанр репрезентации, который дает нам семиотически богатый объем текстов и дискурсов, подпитывающих динамичную культуру потребления. Во-вторых, знаменитость - это также дискурсивный эффект; то есть селебрити, пройдя медийный режим репрезентации, переизобретаются заново. Быть упакованным в этот режим репрезента- 
ции - "быть прославленным" - значит подвергнуться серьезным внутренним и внешним изменениям. Процесс селебритизации рассматривается здесь как преобразующий, но с заметно различным политическим значением, варьирующим от условной формы предоставления прав на самовыражение до способа эксплуатации или объективации. В-третьих, знаменитость, которая является объективированным результатом этого дискурсивного эффекта, сама по себе - товар, как и любой другой коммерческий продукт, который может производиться и продаваться, а потому он может окупить или не окупить инвестиции, разработку, стратегическое планирование и диверсификацию продуктов. В самом прагматичном варианте знаменитость является чьей-то коммерческой собственностью, что имеет основополагающее значение для карьеры и стратегий ее поддержания. Наконец, знаменитость - это также и культурный феномен со своей социальной функцией. Знаменитости не только участвуют в создании сообществ (фан-группы или субкультуры), не только поддерживают культуру знаменитостей и социальные сети вокруг них, они также участвуют в формировании социальных ожиданий в повседневной жизни. Тернер утверждает, что культура знаменитостей - это одна из тех областей, по которой мы можем проследить новую роль СМИ как генератора или автора социальных идентичностей. СМИ кажутся способными продвигать свои собственные конструкции идентичности, например, в качестве побочного продукта набора участников для реалити-шоу или через другие формы индустриально произведенных знаменитостей [Turner, 2010].

\section{Интервьюирование селебрити}

Интервью со знаменитостью можно рассматривать как особый вид интервью с элитой, хотя термин "элита" в данном случае следует использовать с осторожностью в связи с заменой власти владением культурным, экономическим, социальным или символическим капиталами.

Как утверждал Тернер [Turner, 2010: 13], в исследованиях знаменитостей преобладает анализ текста, и в меньшей степени распространен дискурсивный анализ. Тернер объяснял эту узкую направленность эмпирического анализа огромным объемом текстов, сформированных культурой знаменитостей, что подтверждают и другие исследователи селебрити [Dyer, 2007/1979; Holmes, Redmond, 2006]. Это порождает несколько проблем: прежде всего, узкую мультидисциплинарную основу, где могут состояться такие исследования. Кроме того, текстуальный анализ часто не может в достаточной степени различать самоописания и журналистские отчеты, которые СМИ предоставляют своим читателям [Turner, 2010: 15]. Обе сферы подпитывают друг друга: СМИ цитируют селебрити, чтобы легитимировать их рассказы, пока читатели ищут в них эмпирические или текстуальные свидетельства пути к успеху. Вместо этого Коулдри [Couldry, 2012: 37] предлагает начать с практик этой группы, задаваясь вопросом: что такое селебрити (индивиды, группы, учреждения) в целом ряде ситуаций и контекстов? Каковы практики индивидов, которые стремятся стать как можно ближе к знаменитостям, например, при встрече с ними в реальной жизни? Напротив, что предпринимают, чтобы избегать знаменитостей в своей повседневной жизни? Какие коммуникативные и репрезентативные приемы, используемые на политической сцене и в СМИ, способ- 
ствуют тому, чтобы политическая элита и селебрити пользовались популярностью у широких масс? Эти вопросы открывают подход к знаменитостям вне текстуального анализа - в отличие от наблюдений менеджеров, папарацци, фотографов, блогеров и журналистов, и собственно интервью с самими знаменитостями.

Глубинные интервью со знаменитостями уже укоренились в исследовательской практике как метод. Например, можно вспомнить исследование, посвященное американским знаменитостям, под руководством Майкла Иэна Борера [Borer, 2006] - социолога-урбаниста, изучавшего Фенуэй Парк, резиденцию бейсбольной команды Бостон Ред Сокс. Его методы сбора данных включали наблюдения и интервью с бейсболистами, владельцами клуба, болельщиками и людьми, которые жили по соседству. Существенная часть его проекта - проведение интервью с известными бейсболистами. В качестве другого примера можно привести исследования французского социолога Виолэн Руссель [Roussel, 2007; Roussel, Lechaux, 2010] об антивоенном движении в США, в котором участвовали около восьмидесяти известных художников и актеров, таких как Сьюзан Сарандон и Шон Пенн, выступавших против войны в Ираке. Руссель рекрутировала интервьюируемых через Голливуд, проводила интервью face-to-face и по телефону. Известно также исследование психологов Донны Рокуэлл и Дэвида Джайлза [Rockwell, Giles, 2009], занимавшихся вопросами феноменологии славы на основе 15 интервью с американскими знаменитостями из сфер телевидения, индустрии развлечений, кинематографа, мира спорта и музыки, а также из правительства, бизнеса, области права и издательского дела. Дриссенс, в свою очередь, провел 29 глубинных интервью с фламандскими знаменитостями и проанализировал тактики "провокаций СМИ" против одной из них [Driessens, 2013c], а также исследовал, как и почему проинтервьюированных знаменитостей называют "знаменитыми фламандцами", и их оценки этого ярлыка [Driessens, 2013а]. Однако в целом интервью как метод изучения знаменитостей до сих пор использовался довольно редко. Как заметил Коулдри [Couldry, 1999: 59], исследования обнаруживают лишь незначительное внимание к практикам людей, обладающих экономическим и культурным капиталом, по сравнению с обилием материалов о культурных и медийных практиках рабочего класса. Большая часть исследований посвящена потреблению селебрити фанатами [Gray et al., 2007] или социально-культурному влиянию знаменитостей [Elliott, 2011], но не изучению знаменитостей как социальных агентов и респондентов.

Дриссенс дает свое объяснение тому факту, что академическое внимание фокусируется на "малоимущих" во всех смыслах, полагая, что в конечном итоге исследовательская повестка определяется поиском путей по наделению людей социальными правами. Но было бы справедливо и обратное - оспаривание приписанного или вмененного, по Роджеку, статуса элиты для селебрити, демистификация их положения и принципов их власти, в чем, по мнению Кезар [Kezar, 2003: 397], преуспели скорее журналисты, а не исследователи.

Доступ к знаменитостям. Как и в случае с элитами, получение доступа к знаменитостям может потребовать особых усилий и связано с потенциальными проблемами. Во-первых, у знаменитостей обычно “слишком много интервью». Во-вторых, 
доступ к ним и повестку их дня часто строго контролируют гейткиперы - менеджеры или пиар-сотрудники.

В литературе описан феномен усталости от исследований, особенно маркетинговых, и когда интервьюируемые, участвуя в исследовании, не видят в дальнейшем изменений, которые они ожидали, усталость от исследований, скорее всего, накапливается [Clark, 2008]. Но знаменитости не подвергаются чрезмерным исследованиям; как раз наоборот. Они тратят много времени и энергии на интервью с прессой, но их мотивация к участию в академических исследованиях низка. Кроме того, такие интервью обычно не дают им прямой отдачи с точки зрения повышения узнаваемости в СМИ, какой-то коммерческой ценности или общественного внимания. А если исследования к тому же носят критический характер, они могут рассматриваться как угроза публичным и тщательно созданным репрезентациям.

В этой связи Дриссенс [Driessens, 2014] выдвигает важнейший руководящий принцип: необходимость подчеркивать различный характер академического интервьюирования по сравнению с журналистским интервью по содержанию и форме. В приглашениях знаменитостям важно отразить цель и ценность интервью (и возможно исследования; см. также [Lilleker, 2003]). Также может быть полезно объяснить, как и почему они были выбраны для интервью: обозначить теоретические основания или их связь с темой исследования, дав понять, что мотивы лежат вне плоскости собыйтий их личной жизни.

Широкий набор тем, возможность подробно отвечать, реагируя на интервьюеpa, Гилдинг [Gilding, 2010] назвал "терапевтическим шаблоном", который также может стимулировать мотивацию элит к участию в социальных исследованиях. Интервью для прессы больше похожи на институционализированную “форму исповеди, оформленную конкретными нормами, процедурами и правилами" [Roussel, Lechaux, 2010: 7]. Однако этот медийный шаблон также возможен и в социологических интервью, когда представители селебрити используют его как апробированную мотивацию включиться в исследование [Gilding, 2010].

Проблема гейткиперов. Кроме усталости от интервью, исследователи также должны иметь дело с гейткиперами, ограничивающими доступ к знаменитостям. Как и другие представители элиты, знаменитости регламентируют доступ к себе при содействии одного или нескольких человек, занимающихся их повесткой дня и связями с общественностью [Gamson, 1994]. Степень профессионализма этих культурных посредников варьируется. Как сообщает из своего опыта Дриссенс, роли этих культурных посредников могут значительно различаться: некоторые держатся в тени, выступая в качестве посреднического звена для знаменитостей, которые по-прежнему принимают все решения, в то время как другие более плотно контролируют ситуацию вокруг селебрити [Driessens, 2014]. В большинстве случаев невозможно обойти рамки этих культурных посредников. Редко можно найти контактные данные знаменитостей в сети или в справочниках; обычно доступ может быть получен, если связаться с офисом артистов или их работодателем.

В связи с этим важно, чтобы приглашения на интервью были интересны не только знаменитостям, но и их менеджменту. Возможным решением в этой ситуации может быть - подчеркнуть конфиденциальность запроса и возможность 
анонимности в исследовательских отчетах, особенно когда ясно, что исследование нацелено на раскрытие непубличных практик или когда речь идет о конфиденциальной информации, такой как религиозные, этические или политические взгляды [Ferris, 2004: 10]. Как правило, также лучше быть гибким в отношении времени и места собеседования: даже когда получено только полчаса вместо запрошенных полутора, это может оказаться результативным или быть продлено, если интервьюируемый заинтересовался и получает удовольствие от интервью.

Дриссенс делится тремя возможными способами получить доступ к знаменитостям без посредников. Вначале он использовал свою социальную сеть, связавшись с рядом журналистов и сотрудников телекомпаний, которые передали мобильный номер и/или адреса электронной почты знаменитостей. Другая возможность - связаться со знаменитостями напрямую через социальные сети, отправив им сообщение. Наконец, рекомендуется отбор снежным комом [Driessens, 2014]. Все стратегии имеют свои преимущества, увеличивая шанс на участие [см. Clark, 2008: 955].

Еще одна проблема связана с тем, что публичные высказывания селебрити, записанные как звуковые фрагменты для новостей в СМИ, сокращаются с течением времени: выступающие адаптируют свое общение под стиль этой культуры, уменьшая сложность и длину своих высказываний. Исследователи, берущие интервью у элит, таких как политики или селебрити, обычно мало интересуются этими звуковыми фрагментами, ведь они стремятся получить более подробные данные, которые дают больше объяснений и позволяют критически оценивать практику причастных к культуре знаменитостей. Другими словами, вопрос заключается в том, как избежать поверхностных и заранее сформулированных нарративов и получить подлинные и искренние ответы; при этом он остается открытым ввиду дискуссии о содержании "настоящих" ответов.

Как мы можем оценить достоверность полученных данных через подробные интервью со знаменитостями? Например, Дриссенс утверждает, что правдивость или подлинность ответов - не самое главное, это вторично по отношению к тому факту, что в ходе интервью мы можем заглянуть в закрытую субкультуру селебрити и узнать, как они субъективно воспринимают свой социальный мир [Drissens, 2014]. В связи с этим интервью знаменитостей ничем не отличается от интервьюирования любой другой социальной группы. Единственное различие состоит в том, что знаменитости обычно хорошо умеют давать интервью и более осознанно строят свою самопрезентацию [Borer, 2006: 3].

Как объясняет Борер [Borer, 2006: 3], термин "интервью" активирует определенные рамки и нарративные репертуары представителей элит, регулярно участвующих в таких диалогах. В связи с этим крайне важно предварительно объяснять, что природа, виды вопросов и возможные и ожидаемые ответы на академическом и журналистском интервью отличаются. По этой причине Дриссенс, например, начинает коммуникацию с открытых и широких вопросов, которые позволяют селебрити задуматься о статусе знаменитостей. Борер [Borer, 2006: 4] также советует исследователям сравнить данные интервью с тем, что известно публике и было опубликовано в СМИ ранее. Эта триангуляция данных может продемонстрировать различия, но не обязательно гарантирует какую-либо "истину" 
относительно данных исследования или интервью в СМИ. Тем не менее знание таких различий делает исследование более прозрачным и объемным.

Еще одна проблема заключается в том, чтобы определить, какие внутренние персонажи говорят во время интервью. Можно различить следующие образы знаменитостей: публичный, репрезентируемый образ частной персоны и "реальное» частное лицо [Dyer, 2004/1986; Holmes, 2005]. Публичная личность - знаменитость в том виде, в каком она известна в публичной сфере. Репрезентируемый образ частной персоны - это то, какими знаменитости и их окружение хотят, чтобы зрители их видели в пределах управления репрезентацией. Наконец, "реальное" частное лицо может быть обнаружено за кулисами, в частных помещениях, но иногда его приоткрывают папарацци и журналисты, нарушающие границы конфиденциальности. "Настоящее" частное лицо является наиболее деликатным не только с точки зрения поиска стратегий его достижения, но также и с точки зрения оценки того, говорит ли в принципе этот персонаж и когда, в каком контексте он обнаруживается во время интервью. Вводными и рефлексивными вопросами можно попытаться высвободить "реальное" частное лицо, чтобы услышать рассказ о публичных и репрезентируемых частных персонах или масках селебрити с его точки зрения. Однако, как подчеркивает Дриссенс [Driessens, 2014], независимо от того, какой человек говорит, отправная точка и повторяющаяся тема интервью - это человек как знаменитость; интервьюер должен подтвердить, что селебрити все контролирует [Mikecz, 2012]. При этом, безусловно, знаменитости и другие представители элиты могут вынудить интервьюера чрезмерно озаботиться установлением позитивного взаимопонимания [Ostrander, 1993: 19].

\section{Между публичным, репрезентируемым и частным:}

стратегии интервьюирования селебрити

Раскрытие многомерной персоны селебрити в процессе интервьюирования имеет отсылку к понятию популярности как искусству создавать узнаваемость. Культурный деятель строит свой профиль из доступных образов, предоставленных потребительской культурой, и собирает их воедино путем ремикса и повторного присвоения их смысла - так, чтобы совокупный образ оживал для аудитории и превращался в конечном итоге в персону. Этот процесс напоминает субкультурный “бриколаж»: из имеющихся ресурсов член субкультуры создает или косплеит узнаваемый стиль, переделывая и переименовывая множество найденных и переработанных черт. Эти стили бриколажирования имеют два измерения, которые напрямую связывают их с исследованиями личностей в русле persona studies [Marshall et al., 2015]. Во-первых, вовлечение в конструирование такого стиля несет след индивидуальности. Во-вторых, стиль рассчитан на форму публичной демонстрации и самовыражения. Таким образом, эффектная субкультура или культурная сцена, что концептуально более актуально,- - это условие публичной персонификации, необходимое для передачи определенных смыслов индивиду, воспользовавшемуся институциональными средствами и публичными дискурсами. С очевидностью, в этом процессе фокус persona studies - в подчеркнутой агентности представителей той или иной сцены, добивающихся на своем поприще успеха. Хайних называет этот процесс сингуляризацией [Heinich, 2012], анали- 
зируя в исследовании персон то, как они себя "рекламируют", "репрезентируют" и стратегически "разыгрывают" свою личность. Подобным образом исследование персоны-селебрити нацелено на изучение стратегий вывода на первый план, сокрытия либо манипуляций относительно версий публичных, репрезентируемых частных или сугубо частных лиц отдельных знаменитостей.

В качестве эмпирической иллюстрации рассмотрим стратегии публичного интервьюера знаменитостей, отчасти и самого приобретшего за счет успеха своей деятельности статус селебрити, - Юрия Дудя, российского журналиста, видеоблогера, ведущего ютуб-канала "ВДудь" ${ }^{5}$ с аудиторией в 9,5 млн подписчиков. В фокусе нашего интереса будут два интервью: «Ивлеева - про Элджея, секс и пластику" (2018 г., хронометраж 59 минут) и "MORGENSHTERN — главный шоумен России-2020" (2020 г., хронометраж 2 часа 47 минут).

Интервью с Анастасией Ивлеевой начинается фразой интервьюера: “Сейчас ты главная девушка русского YouTube",- фиксирующей точку отсчета для разговора (успех достигнут, режим констатации). Затем ведущий увлекает в прошлое, когда об успехе только мечталось и героиня не разменивалась на быстрые деньги, стартуя с позиции хостес в клубе, удачного и невозвращенного займа. Следующая тема - отношение к блогерам вообще, дальним и ближним. В фокусе разговора труд блогеров, жизнь в режиме обязательств, переездов, командировок. И вдруг вопрос Дудя: "А секс в командировке был?"- вздох, передергивание плечами, легкая улыбка, за которой следует ответ: “Был». Публичный образ мгновенно перекроился в пользу... частного? Отнюдь, в пользу продуманного репрезентируемого образа по определению частной, даже интимной сферы, ставшей в разговоре предметом дальнейшего обсуждения на примерах других селебрити и обобщений относительно молодежи. Прием интервьюера работает на заземление пафосного образа главной девушки YouTube, поскольку после этой интервенции Ивлеева уже говорит о себе: "Я народный человек, девчонка с яйцами". Следующая тематическая итерация в интервью со стороны интервьюера вновь номинирует героиню: “Ты звезда, мечтала попасть на ТВ". И после этих качелей статусов мы как зрители получаем ценное стратегическое признание с экрана в том, что Ивлеева рационально выстраивает стратегию завоевания публичной сферы, понимая, что "когда и ТВ, и интернет в параллель показывают твое лицо, это усиливает эффект узнавания... К тебе есть внимание... Не хочу останавливаться, хочу лететь вперед на локомотиве, а вагончики будут приклеиваться постепенно...".

Интервью с Моргенштерном заняло значительно больше времени, но как и с Ивлеевой интервьюер менял локации, регистры частного и публичного, включал телесные диспозитивы, обсуждая с обоими инвестиции в белоснежные виниры, сексуальные переживания, вовлекая Моргенштерна в физические силовые упражнения, что выравнивало позиции в соревновании в спортивной комнате дома. Телесная сонастройка во время интервью становится узнаваемым приемом, эффект которого накапливается, давая доступ к большим степеням доверия и дискурсивной свободы. Интервью с Ивлеевой заканчивается вопросом про татуировку и предложением для зрителей придумать для нее сюжет, что заколь-

\footnotetext{
${ }^{5}$ Канал «вДудь»: https://www.youtube.com/channel/UCMCgOm8GZkHp8zJ6I7_hluA.
} 
цовывает открытость героини для зрителей. Но соблазнительный шанс оставить свой след в виде идеи для татуировки на теле героини можно рассматривать и как пример ее объективизации и символической власти сообщества фанатов.

Моргенштерна интервьюер проводит по близкому сценарию, но значительно более расширенному и дискурсивно адаптированному к скандальной стилистике героя - первой фразой Дудя становится: “Ты сейчас из всех щелей". Метафора подтягивает образ маленького, непрошенного, но очень настойчивого существа. Дудь, ссылаясь на проведенные интервью с другими селебрити, в том числе и с политиками, предлагает собеседнику тест на самопрезентацию: “...будут зрители, которые <...> включат выпуск и зададут вопрос: кто это такой? Как бы ты себя для них представил?» Ответ героя: “Алишерка меня зовут. Привет!» Интервьюер намеренно оттянул номинацию собеседника ("Ты сейчас главный шоумен страны») на более поздние итерации разговора, проявляя масштаб самопрезентации героя. Дальнейшие усилия интервьюера связаны с выяснением амбиций и притязаний героя, и в ходе разговора обнаруживается, что концерт мечты Моргенштерна оупен-эйр фестиваль с военным вертолетом. Однако путь к этому апофеозу вполне рационально выверен - эксплуатировать "эмоциональную карусель": "Главное, чтобы творчество вызывало эмоцию. Неважно какую. Если эмоцию вызывает - ты победил. <...> неважно какая». Выявляет интервьюер еще одну важную стратегию выращивания успеха - коллаборации с другими музыкантами, записи совместных музыкальных композиций, как бы делящихся наработанными капиталами популярности (как об этом писал упомянутый выше Бурстин [Boorstin, 1962/1992]). Для завершения этого интервью особенно подходит традиционная для Дудя геймификация - конкурс для подписчиков с призом в виде мерча Моргенштерна, предлагающим посоветовать герою, с кем ему не стоит фитовать, то есть совместно записывать музыкальные композиции. Таким образом, эпатажный публичный образ шоумена благодаря интервенциям интервьюера обнаруживает персонифицированные характеристики: мы видим амбициозного музыканта, расчетливого строителя собственного успеха, осознающего риски, имевшего опыт употребления наркотиков, но как бы выбирающего здоровый образ жизни, некогда промискуитетного героя шоу-сцены и нежного возлюбленного, а теперь и мужа девушки Диляры, пересыпающего речь обсценной лексикой, имеющего или демонстрирующего молодежные ценности селебрити - то есть объемную по раскрытым чертам персону.

\section{Заключение}

Суммируя рассмотренные аспекты интервьюирования, можно обнаружить общую для изучения элит и селебрити проблему - доступа к человеку. Известно, что политическую и предпринимательскую элиту достаточно сложно привлечь к участию в исследовании, особенно если мандат на вход в исследовательское поле зарезервирован за ней. Для доступа к руководителям корпораций, членам совета директоров требуется пройти через личных помощников, секретарей и даже телохранителей [Gilding, 2010]. Личная встреча для интервью может требовать длительного планирования. Кроме того, сбор данных от представителей элит требует высокого уровня социального и культурного капиталов со стороны исследователя, а также опыта 
и полномочий. Эти формы капитала позволяют исследователям установить взаимопонимание с информантами, что является предпосылкой для эффективного сбора данных [Ostrower, 1995]. Необходимость предъявлять эти виды капитала требует продуманной стратегии самопрезентации, что само по себе непросто. Некоторые исследователи предлагают озвучивать при контакте свою должность в академической системе или исследовательской индустрии, если их статус в профессиональном контексте равен статусу представителя элиты, которую они изучают [Conti, O’Neil, 2007; Hermanowicz, 2002]. Поскольку большинство исследователей не могут реально заявить, что они обладают такой же властью, влиянием или богатством, как руководители корпораций, топ-менеджеры или предприниматели, то единственной областью, выравнивающей различия в статусе, являются экспертные знания. Исключение составляют несколько известных ученых, родившихся в семьях, наделенных властью и привилегиями, как, например, Эдвард Дигби Балтцелл: его исследовательский сюжет и одновременно собственная социальная среда-белая англосаксонская протестантская аристократия [Baltzell, 1964].

Обращения к интервью с селебрити не в журналистских, а в исследовательских целях достаточно редки. Первая причина - упомянутая сложность доступа к ним, а также сложившаяся традиция дискурсивного анализа текстуальных следов знаменитостей [Turner, 2010]. Другая причина связана с предпочтениями исследовательского выбора в пользу низших классов, но не элит: рабочий класс опережал элиты по вниманию к их культуре [Couldry, 1999]. Однако встречаются разные позиции относительно того, отличается ли интервьюирование элит от интервьюирования других групп населения. С одной стороны, есть мнение о разных методологических и этических проблемах изучения тех, кто вверху и внизу социальной пирамиды [Leech 2002; Aberbach, Rockman, 2002], с другой - мнение об отсутствии таких различий [Smith, 2006].

Интервьюирование знаменитостей имеет специфическую особенность: частые журналистские интервью приводят к шаблонности самопрезентации представителей этой группы. Одновременно с этим высокая вовлеченность в медийные интервью снижает их мотивацию к участию в академических исследованиях. Проблема доступа к селебрити для социологического интервьюирования может быть решена через гейткиперов, социальные сети или с использованием метода снежного кома через первичное ключевое знакомство. В работе с этой группой важен эпистемологический момент - через дискурс persona studies: различение различных перформативных уровней селебрити: публичной личности, репрезентируемой частной личности и "реальной" частной личности.

\section{Список литературы (References)}

Aberbach J. D, Rockman B. A. (2002) Conducting and Coding Elite Interviews. PS: Political Science and Politics. Vol. 35. No. 4. P. 673-676. https://doi.org/10.1017/ S1049096502001142.

Adler M. (1985) Stardom and Talent. The American Economic Review. Vol. 74. No. 1. P. $208-212$. 
Adorno T. (1991) The Culture industry: Selected Essays on Mass Culture. New York, NY; London, UK: Routledge.

Alberoni F. (1962/2006) The Powerless ‘Elite': Theory and Sociological Research on the Phenomenon of the Stars. In: Marshall P.D. (Ed.) The celebrity culture reader. New York, NY: Routledge. P. 108-123.

Baltzell E. Digby (1964) The Protestant Establishment: Aristocracy and Caste in America. New York, NY: Random House.

Baym N. K. (1993) Interpreting Soap Operas and Creating Community: Inside a Computer Mediated Fan Culture. Journal of Folklore Research. Vol. 30. No. 2-3. P. 143-176.

Boorstin D. (1962) The Image: A Guide to Pseudo-Events in America. New York, NY: Harper.

Borer M. I. (2006) Interviewing Celebrities: Strategies for Getting beyond the Sound Bite. Annual Meeting of the American Sociological Association. Montréal Convention Center, Montréal, Québec: All Academic.

Bourdieu P., Coleman J. S., Coleman Z. W. (1991) Social Theory for a Changing Society. New York, NY: Westview Press.

Braudy L. (1986) The Frenzy of Renown: Fame and Its History. New York, NY: Oxford University Press.

Burt R. S. (2000) The Network Structure of Social Capital. Research in Organizational Behavior. Vol. 22. P. 345-423. https://doi.org/10.1016/S0191-3085(00)22009-1.

Clark T. (2008) ‘We’re Over-Researched Here!’ Exploring Accounts of Research Fatigue within Qualitative Research Engagements. Sociology. Vol. 42. No. 5. P. 953-970. https://doi.org/10.1177/0038038508094573.

Cochrane A. (1998) Illusions of Power: Interviewing Local Elites. Environment and Planning A: Economy and Space. Vol. 30. No. 12. P. 2121-2132. https://doi. org/10.1068/a302121.

Conti J. A., O’Neil M. (2007) Studying Power: Qualitative Methods and the Global Elite. Qualitative Research. Vol. 7. No. 1. P. 63-82. https://doi.org/10.1177/ 1468794107071421.

Couldry N. (1999) Inside Culture: Re-imagining the Method of Cultural Studies. London, UK: SAGE.

Couldry N. (2012) Media, Society, World: Social Theory and Digital Media Practice. Cambridge, UK: Polity.

Cowen T. (2000) What Price Fame? Cambridge, MA: Harvard University Press.

Cunningham-Sabot E. (1999) Dr. Jekyl, Mr. H(i)de: The Contrasting Face of Elites at Interview. Geoforum. Vol. 30. No. 4. P. 329-335. 
Currid-Halkett E. (2010) Starstruck: The Business of Celebrity. New York, NY: Faber \& Faber.

Delaney K. (2007) Methodological Dilemmas and Opportunities in Interviewing Organizational Elites. Sociology Compass. Vol. 1. No. 1. P. 208-221. https://doi.org/ 10.1111/j.1751-9020.2007.00028.x.

Dexter L. (2006) Elite and specialized interviewing. Colchester, UK: ECPR Press.

Driessens O. (2013a) Being a Celebrity in Times of Its Democratisation: A Case Study from the Flemish Region. Celebrity Studies. Vol. 4. No. 2. P. 249-253. https://doi.org/ 10.1080/19392397.2013.791050.

Driessens O. (2013b) The Celebritization of Society and Culture: Understanding the Structural Dynamics of Celebrity Culture. International Journal of Cultural Studies. Vol. 16. No. 6. P. 641-657. https://doi.org/10.1177/1367877912459140.

Driessens O. (2013c) ‘Do (Not) Go to Vote!' Media Provocation Explained. European Journal of Communication. Vol. 28. No. 5. P. 556-569. https://doi.org/10.1177/ 0267323113493253.

Driessens O. (2013d) Celebrity Capital: Redefining Celebrity Using Field Theory. Theory and Society. Vol. 42. No. 5. P. 543-560. https://doi.org/10.1007/ s11186-013-9202-3.

Driessens O. (2014) Expanding Celebrity Studies' Research Agenda: Theoretical Opportunities and Methodological Challenges in Interviewing Celebrities. Celebrity Studies. Vol. 6. No. 2. P. 192-205. https://doi.org/10.1080/19392397.2014.970653.

Dyer R. (2004/1986) Heavenly Bodies: Film Stars and Society (2nd edn). New York, NY: Routledge.

Dyer R. (2007/1979) Stars (2nd ed.). London, UK: British Film Institute.

Frank R. H., Cook P. J. (1995) The Winner-Take-All Society: Why the Few at the Top Get So Much More than the Rest of Us. New York, NY: Penguin Books.

Elliott A. (2011) ‘I Want to Look Like That!’ Cosmetic Surgery and Celebrity Culture. Cultural Sociology. Vol. 5. No. 4. P. 463-477. https://doi.org/10.1177/1749975510391583.

Ferris K. O. (2004) Seeing and Being Seen: The Moral Order of Celebrity Sightings. Journal of Contemporary Ethnography. Vol. 33. No. 3. P. 236-264. https://doi.org/ Э10.1177/0891241604263585.

Gamson J. (1994) Claims to Fame: Celebrity in Contemporary America. Berkeley, CA: University of California Press.

Goldman E. F., Swayze S. (2012) In-Depth Interviewing with Healthcare Corporate Elites: Strategies for Entry and Engagement. The International Journal of Qualitative Methods. Vol. 11. No. 3. P. 230-243. https://doi.org/10.1177/160940691201100304.

Gray J., Sandvoss C., Harrington C. L. (eds.) (2007) Fandom: Identities and Communities in a Mediated World. New York, NY: New York University Press. 
Grinin L.E. (2012) Celebrities as a New Elite of Information Society. Social Evolution \& History. Vol. 11. No. 1. P. 124-153.

Gilding M. (2010) Motives of the Rich and Powerful in Doing Interviews with Social Scientists. International Sociology. Vol. 25. No. 6. P. 755-777. https://doi.org/ $10.1177 / 0268580909351323$.

Hartmann M. (2002) Der Mythos von den Leistungseliten. Spitzenkarrieren und soziale Herkunft in Wirtschaft, Politik, Justiz und Wissenschaft. Frankfurt: Campus Verlag.

Harvey W.S. (2010) Methodological Approaches for Interviewing Elites. Geography Compass. Vol. 4. No. 3. P. 193-205. https://doi.org/10.1111/j.1749-8198. 2009.00313.x.

Hermanowicz J. C. (2002) In the Shadows of Giants: Identity and Institution Building in the American Academic Profession. Advances in Life Course Research. Vol. 7. P. 133-162. https://doi.org/10.1016/S1040-2608(02)80033-8.

Heinich N. (2012) De la Visibilité: Excellence et Singularité en Régime Médiatique. Paris, FR: Editions Gallimard.

Hertz R., Imber J. B. (Eds.) (1995) Studying Elites Using Qualitative Methods. Thousand Oaks, CA: Sage.

Hirsch P. (1995) Tales from the Field. In: R. Hertz, Imber J. B. (eds.) Studying Elites Using Qualitative Methods. Thousand Oaks, CA: Sage. P. 72-79.

Holmes S. (2005) ‘Off-Guard, Unkempt, Unready’? Deconstructing Contemporary Celebrity in Heat Magazine. Continuum: Journal of Media \& Cultural Studies. Vol. 19. No. 1. P. 21-38. https://doi.org/10.1080/1030431052000336270.

Holmes S., Redmond S. (Eds.) (2006) Framing Celebrity: New Directions in Celebrity Culture. London, UK: Routledge.

Jenkins H. (2006) Fans, Bloggers and Gamers. New York, NY: New York University Press.

Kezar A. (2003) Transformational Elite Interviews: Principles and Problems. Qualitative Inquiry. Vol. 9. No. 3. P. 395-415. https://doi.org/10.1177/1077800403009003005.

Leech B. L. (2002) Interview Methods in Political Science. PS: Political Science and Politics. Vol. 35. No. 4. P. 663-664. https://doi.org/10.1017/S1049096502001117.

Lilleker D. (2003) Interviewing the Political Elite: Navigating a Potential Minefield. Politics. Vol. 23. No. 3. P. 207-214. https://doi.org/10.1111/1467-9256.00198.

MacDonald G. M. (1988) The Economics of Rising Stars. American Economic Review. Vol. 78. No. 1. P. 155-166.

Marshall D.P. (1997) Celebrity and Power: Fame in Contemporary Culture. Minneapolis, MN: University of Minneapolis Press.

Marshall C., Rossman G. (1999) Designing Qualitative Research. Thousand Oaks, CA: Sage. 
Marshall D. P. (2006) New Media - New Self: The Changing Power of Celebrity. In: Marshall D.P. (ed.) The Celebrity Culture Reader. New York, NY: Routledge.

Marshall D. P. (2010) The Promotion and Presentation of the Self: Celebrity as Marker of Presentation Media. Celebrity studies. Vol. 1. No. 1. P. 35-48. https://doi.org/ 10.1080/19392390903519057.

Marshall D. P (2014) Celebrity and Power: Fame in Contemporary Culture. Minneapolis, MN: University of Minnesota Press.

Marshall D. P., Moore Ch., Barbour K. (2015) Persona as Method: Exploring Celebrity and the Public Self through Persona Studies. Celebrity Studies. Vol. 6. No.3. P. 288305. https://doi.org/10.1080/19392397.2015.1062649.

Mikecz R. (2012) Interviewing Elites: Addressing Methodological Issues. Qualitative Inquiry. Vol. 18. No. 6. P. 482-493. https://doi.org/10.1177/1077800412442818.

Morris Z. S. (2009) The Truth about Interviewing Elites. Politics. Vol. 29. No. 3. P. 209217. https://doi.org/10.1111/j.1467-9256.2009.01357.x.

Odendahl T., Shaw A. (2002) Interviewing Elites. In: Gubrium J. E., Holstein J. A. (Eds.) Handbook of Interviewing Research. Thousand Oaks, CA: Sage. P. 299-316.

Ostrander S. A. (1993) "Surely You're Not in This Just to Be Helpful”: Access, Rapport, and Interviews in Three Studies of Elites. Journal of Contemporary Ethnography. Vol. 22. P. 7-27. No. 1. https://doi.org/10.1177/089124193022001002.

Ravid G., Currid-Halkett E. (2013) The Social Structure of Celebrity: An Empirical Network Analysis of an Elite Population. Celebrity Studies. Vol. 4. No. 2. P. 182-201. https://doi.org/10.1080/19392397.2013.791047.

Richards D. (1996) Elite Interviewing: Approaches and Pitfalls. Politics. Vol. 16. No. 3. P. 199-204. https://doi.org/10.1111/j.1467-9256.1996.tb00039.x.

Redmond S. (2010) Avatar Obama in the Age of Liquid Celebrity. Celebrity Studies. Vol. 1. No. 1. P. 81-95. https://doi.org/10.1080/19392390903519081.

Rojek C. (2001) Celebrity. London: Reaktion.

Rosen S. (1981) The Economics of Superstars. American Economic Review. Vol. 71. No. 5. P. $845-858$.

Rockwell D., Giles D. C. (2009) Being a Celebrity: A Phenomenology of Fame. Journal of Phenomenological Psychology. Vol. 40. No. 2. P. 178-210.

Roussel V. (2007) Occupational Logics and Political Commitment: American Artists against the Iraq War. International Political Sociology. Vol. 1. No. 4. P. 373-390. https://doi.org/10.1111/j.1749-5687.2007.00027.x.

Roussel V., Lechaux B. (2010) Voicing Dissent: American Artists and the War on Iraq. London, UK: Routledge. 
Savage M., Williams K. (2008) Elites: Remembered in Capitalism and Forgotten by Social Sciences. The Sociological Review. Vol. 56. No. 1 (suppl.). P. 1-24. https://doi. org/10.1111\%2Fj.1467-954X.2008.00759.x.

Seidman I. (1998) Interviewing as Qualitative Research: A Guide for Researchers in Education and the Social Sciences ( $2^{\text {nd }}$ ed.). New York, NY: Teachers College Press.

Smith K. E. (2006) Problematising Power Relations in 'Elite' Interviews. Geoforum. Vol. 37. No. 4. P. 643-653. https://doi.org/10.1016/j.geoforum.2005.11.002.

Sternberg R.J. (1999) Intelligence as Developing Expertise. Contemporary Educational Psychology. Vol. 24. No. 4. P. 359-375. https://doi.org/10.1006/ceps.1998.0998.

Turner G., Bonner F. J., Marshall D. P. (2000) Fame Games: The Production of Celebrity in Australia. Melbourne: Cambridge University Press.

Turner G. (2004) Understanding Celebrity. London: Sage.

Turner G. (2010) Approaching Celebrity Studies. Celebrity Studies. Vol. 1. No. 1. P. 1120. https://doi.org/10.1080/19392390903519024.

Thomas R. (1995) Interviewing Important People in Big Companies. In: Hertz R., Imber J. (Eds.) Studying Elites Using Qualitative Methods. Thousand Oaks, CA: Sage. P. 3-17. Undheim T. (2003) Getting Connected: How Sociologists Can Access the Hightech Élite. The Qualitative Report. Vol. 8. No. 1. P. 104-128.

Useem M. (1995) Reaching Corporate Executives. In: Hertz R., Imber J. (eds.) Studying Elites Using Qualitative Methods. Thousand Oaks, CA: Sage. P. 18-39.

Welch C., Marschan-Piekkari R., Penttinen H., Tahvanainen M. (2002) Corporate Elites as Informants in Qualitative International Business Research. International Business Review. Vol. 11. No. 5. P. 611-628. https://doi.org/10.1016/S0969-5931(02) 00039-2.

Woods M. (1998) Rethinking Elites: Networks, Space, and Local Politics. Environment and Planning. Vol. 30. No. 12. P. 2101-2119. https://doi.org/10.1068\%2Fa302101.

Yeung H. (1995) Qualitative Personal Interviews in International Business Research: Some Lessons from a Study of Hong Kong Transnational Corporations. International Business Review. Vol. 4. No. 3. P. 313-339. https://doi.org/10.1016/0969-5931(95)00012-0. 